\title{
Care trajectories of chronically ill older adult patients discharged from hospital: a quantitative cross-sectional study using health insurance claims data
}

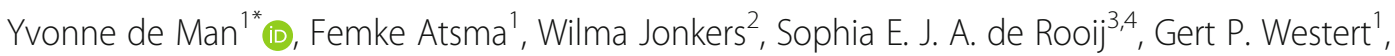
Patrick P. T. Jeurissen ${ }^{1}$ and A. Stef Groenewoud ${ }^{1}$

\begin{abstract}
Background: For older adults, a good transition from hospital to the primary or long-term care setting can decrease readmissions. This paper presents the 6-month post-discharge healthcare utilization of older adults and describes the numbers of readmissions and deaths for the most frequently occurring aftercare arrangements as a starting point in optimizing the post-discharge healthcare organization.

Methods: This cross-sectional study included older adults insured with the largest Dutch insurance company. We described the utilization of healthcare within 180 days after discharge from their first hospital admission of 2015 and the most frequently occurring combinations of aftercare in the form of geriatric rehabilitation, community nursing, long-term care, and short stay during the first 90 days after discharge. We calculated the proportion of older adults that was readmitted or had died in the 90-180 days after discharge for the six most frequent combinations. We performed all analyses in the total group of older adults and in a sub-group of older adults who had been hospitalized due to a hip fracture.
\end{abstract}

Results: A total of $31.7 \%$ of all older adults and $11.4 \%$ of the older adults with a hip fracture did not receive aftercare. Almost half of all older adults received care of a community nurse, whereas less than $5 \%$ received long-term home care. Up to 18\% received care in a nursing home during the 6 months after discharge. Readmissions were lowest for older adults with a short stay and highest in the group geriatric rehabilitation + community nursing. Mortality was lowest in the total group of older aldults and subgroup with hip fracture without aftercare.

Conclusions: The organization of post-discharge healthcare for older adults may not be organized sufficiently to guarantee appropriate care to restore functional activity. Although receiving aftercare is not a clear predictor of readmissions in our study, the results do seem to indicate that older adults receiving community nursing in the first 90 days less often die compared to older adults with other types of aftercare or no aftercare. Future research is necessary to examine predictors of readmissions and mortality in both older adult patients discharged from hospital.

Keywords: Healthcare utilization, Aftercare, Home and community based care and services, Healthcare policy, Hospital/ambulatory care, Long-term care, Hip fracture, Quantitative research methods

\footnotetext{
* Correspondence: Yvonne.deman@radboudumc.nl

${ }^{1}$ Radboud university medical center, Radboud Institute for Health Sciences,

IQ healthcare, P.O. Box 9101, 114, 6500, HB, Nijmegen, the Netherlands

Full list of author information is available at the end of the article
}

(c) The Author(s). 2019 Open Access This article is distributed under the terms of the Creative Commons Attribution 4.0 International License (http://creativecommons.org/licenses/by/4.0/), which permits unrestricted use, distribution, and reproduction in any medium, provided you give appropriate credit to the original author(s) and the source, provide a link to the Creative Commons license, and indicate if changes were made. The Creative Commons Public Domain Dedication waiver (http://creativecommons.org/publicdomain/zero/1.0/) applies to the data made available in this article, unless otherwise stated. 


\section{Background}

Approximately $18 \%$ of people over 75 years old are newly admitted to the hospital annually [1]. These hospitalizations bring substantial risks,. Among older adults who are clinically admitted, irreversible loss of function can arise (this number varies between 30 to 60\%) [2]. These older adult patients are especially at risk of becoming frail. Frail older adult patients are less capable to live independently at home, leading to a greater dependency in daily life, the loss of the ability to care for oneself, an increased mortality risk [3, 4] and an increased healthcare utilization in different care settings [5]. One study reported that a third of frail older adults die within 100 days after discharge from hospital [6].

Research shows that a good transition from hospital to the primary or long-term care setting can decrease readmission rates [7]. However, we currently lack insight in the type and intensity of care that most older adult patients actually receive after a clinical admission and whether this is optimally organized in order to prevent adverse outcomes. Insight into the healthcare utilization of a patient group forms the first crucial step toward improving their healthcare, and is a tool for the identification of potential areas for improvement. This paper therefore aims to present the 6-month post-discharge healthcare utilization of older adult patients and describe the numbers of readmissions and deaths for the most frequently occurring aftercare arrangements as a starting point in optimizing the post-discharge healthcare organization.

We hypothesize that older adults with any type of intensive aftercare would have lower mortality and readmission rates than chronically ill older adult patients who are discharged otherwise.

\section{Methods}

\section{Design}

The design of this study is an observational crosssectional study using health insurance claims data in the period of January 2015-July 2016. Quantitative measures were used in order to gain insight into the healthcare utilization of older adults after their hospital admission and describe the numbers of readmissions and deaths.

\section{Population}

We included subjects insured by the largest Dutch insurance company (30\% market share) with at least one claimed hospital admission in 2015. We selected all patients who were living in one of the company's careoffice regions in 2015. Hence, we were able to analyze the full chain of healthcare, including hospital care, general practitioners care, community nursing, medications, and long-term care. We attempted to define frail older adult patients from our dataset as they are most at risk for adverse events.
Research done by Makai et al. has shown that age, sex, medication use, and being incontinent are predicting variables for frailty when analyzing claims data [8]. We therefore included patients if they were aged 75 and up, used medications from at least two pharmacy-based cost groups [9], which are defined by The National Health Care Institute [10] and used incontinence materials in 2015.

Of the 375,044 insurees that were 75 years or older in $2015,247,529(66 \%)$ were clinically admitted to a hospital. With the additional criteria, we identified 21,258 $(8.7 \%)$ as likely to be frail. This is much lower than the percentages of frailty found in the literature [11] and underpins the belief that the best way to identify frail older adults is by performing a comprehensive geriatric assessment $[12,13]$. Thus, in order to not confuse existing literature we abstain from using the term 'frail' for our subjects and will refer to them as chronically ill older adult patients.

We identified 21,258 hospitalized chronically ill older adult patients. They were clinically admitted at least once in that year to one of 96 different organizations: 87 hospitals and 9 private clinics. In order to obtain a more homogenous group, we also conducted all analyses in a subsample of our selection. We chose older adults clinically admitted with a hip fracture, as this is a typical acute event requiring hospitalization and rehabilitation.

\section{Data}

The insurance company's database contains all claims data and underlying care provided at the level of healthcare activities and performance codes of their insurees. The data also includes information about the healthcare providers, as well as the 4-digit postal codes, age, sex, and marital status of insurees.

Data on socioeconomic status (SES) of 2014 were retrieved from the Social and Cultural Planning Office (SCP) and linked by four digital postal codes to the claims data. SCP calculated social economic status scores based on information regarding education, income, and position in the labor market [14]. The scores resemble the social status of a postal code region, relative to the other regions in the Netherlands.

\section{Procedures and definitions}

For each insuree, all claims under the healthcare law and long-term care act were recovered. Claims under the social support act were not included (these are reimbursed through municipalities). We identified the last day of a patient's first admission in 2015. These included clinical admissions, intensive care unit (ICU), and emergency room (ER) contacts in a hospital or independent treatment centre. The claims database does not include ICD10 codes. In order to determine what the underlying reason for admission was, the healthcare insurance 
company provided us with a reference table where each diagnosis-related group (DRG) was linked to a certain chapter of the ICD-10 codes. We selected all healthcare activities that were registered within a 180 day period after their discharge. As there are thousands of different healthcare activities, we clustered the data according to predefined meaningful categories [15] .

In order to describe the number of deaths and readmissions for different combinations of aftercare, we labeled chronically ill older adult patients according to the type(s) of care they received in the 90 days after admission: geriatric rehabilitation (GR), community nursing $(\mathrm{CN})$, a short stay in a nursing home (ST), and longterm care (LTC). Geriatric rehabilitation (GR) is shortterm and intensive care given by a multidisciplinary team either in a hospital ward or a nursing facility [16]. A person is eligible for GR when they can return home after this treatment. $\mathrm{CN}$ is nursing care at home for patients with an illness or disability. The aim is to ensure that the older adults can stay at home for as long as possible. A short stay (ST) is a temporary stay in a nursing home where people after hospitalization can stay for up to 12 weeks. Patients are eligible for an ST if they need more care than can be provided in the home situation [17]. LTC is intensive care provided at home or in a facility and is only for patients that will need permanent care 24/7. Patients with LTC pay an income-bound contribution to the costs [18].

We chose these four categories, as these are the types of usual aftercare that we believe might ward off readmissions. It was possible for each chronically ill older adult patient to be labeled with more than one category, resulting in multiple combinations of aftercare. For the six most frequently occurring combinations of aftercare, the group without any of these four types and the remaining patients (others) we identified subject characteristics and the readmission and mortality rates in the 90 days and $90-180$ days after admission.

\section{Analyses}

For both samples, means and standard deviations for age; median and ranges for SES, total 2015 spending, and number of morbidities; frequencies and percentages for sex, marital status, types of morbidities, and the three most frequently registered DRGs opened at admission, were calculated. We analyzed the six-month postdischarge healthcare utilization for all FE and FE admitted due to a hip fracture, for hospital care, GP care, long-term care, and community nursing care. We did this by calculating the number and percentage of chronically ill older adult patients with a certain type of treatment and by calculating the average number of treatments per user. To assess group differences, a T-test and a nonparametric equivalent were performed on all continuous variables. A Chi-square test was performed on all categorical variables.

All analyses were performed in SAS Enterprise Guide.

\section{Results}

Healthcare utilization profiles

In Table 1, descriptive statistics for all included chronically ill older adult patients are presented. The average age at the time of admission was 83.8 years and more females than males were clinically admitted (62.1\%). The most common morbidities were hypertension (88.1\%), heart conditions (62.4\%), and high cholesterol (54.8\%). Of all 21,258 chronically ill older adult patients, 505 (2.4\%) died during their first 2015 admission, resulting in a total of 20,753 discharged patients. A total of $12.5 \%$ died during admission or during the 90 days after discharge. The five most common reasons for a hospital admission was injury or poisoning (7.0\%), ischemia, CABG, PCI (6.2\%), cerebrovascular diseases (5.3), diseases of the digestive system (5.2\%), and cardiac arrhythmia (5.5\%).

Table 2 described the post-discharge healthcare utilization. During the six-month period after admission, $51.5 \%$ of all chronically ill older adult patients had a (non-ICU) readmission with a median number of hospital days of 12 . Within the same time-frame, $12.3 \%$ of all patients were admitted to the ER with an average visit of 1.3 times (median 1). Almost half of all chronically ill older adult patients received care of a community nurse, whereas less than $5 \%$ received long-term home care. Up to $18 \%$ received care in a nursing home during the 6 months after discharge. Almost all patients visited their GP at least once, with a median of 7 visits, and in two thirds of the cases, the GP visited the patients at home (median of 3).

Significant differences between the total group of chronically ill older adult patients and chronically ill older adult patients with a hip fracture are: patients with a hip fracture were on average 3 years older, they had a higher healthcare spending in 2015, and more patients were readmitted with almost double the amount of hospital days and more rehabilitation days. Patients suffering from a hip fracture had significantly less outpatient visits, non-invasive diagnostics, and GP consultations compared to the total group of chronically ill older adult patients.

\section{Aftercare combinations and outcomes}

The 6 most frequent combinations of aftercare for GR, $\mathrm{CN}, \mathrm{ST}$, and LTC during the first 90 days are: CN, LTC, $\mathrm{GR}+\mathrm{CN}, \mathrm{CN}+\mathrm{LTC}, \mathrm{GR}$, and ST. These groups are shown in Tables 3 and 4 together with the group of chronically ill older adult patients not receiving any of these four types and the remaining category 'other'. Table 3 depicts the results for the total group of 
Table 1 Baseline characteristics

\begin{tabular}{|c|c|c|c|c|c|c|}
\hline \multirow[b]{2}{*}{ Measure } & \multicolumn{3}{|c|}{ Older adult with any admission in $2015(N=21,258)$} & \multicolumn{3}{|c|}{ Older adult admitted with hip fracture $(N=814)$} \\
\hline & N (\%) & Mean (SD) & Median [Range] & $\mathrm{N}$ & Mean (SD) & median \\
\hline Age & 21,258 & $83.8(5.6)$ & $83[75-104]$ & 814 & $86.7(5.5)^{* * * c}$ & $87[75-101]$ \\
\hline Male & 8066 (37.9) & & & $200(24.6)^{* * *}$ & & \\
\hline SES & 21,258 & $-0.4(1.2)$ & $-0.2[-5.7-2.8]$ & 811 & $-0.3(1.2)^{d}$ & $-0.1[-5.7-2.6]$ \\
\hline Mortality during admission & $505(2.4)$ & & & $23(2.8)$ & & \\
\hline Total 2015 spending, $€$ & 21,258 & $24,793(20,506)$ & $19,045[705-468,772]$ & 814 & $30,283(18,354)^{* * * d}$ & $27,054[1424-177,666]$ \\
\hline \multicolumn{7}{|l|}{ Marital status } \\
\hline Married & $6216(29.2)$ & & & $160(19.7)$ & & \\
\hline Divorced/never been married & $2616(12.3)$ & & & $101(12.4)$ & & \\
\hline Widow (er) & $6031(28.4)$ & & & $292(35.9)$ & & \\
\hline Unknown & $6395(30.1)$ & & & $261(32.1)$ & & \\
\hline Number of morbidities ${ }^{a}$ & 21,258 & $3.8(1.5)$ & $4[2-11]$ & 814 & $3.3(1.3)^{* * * d}$ & $3[2-8]$ \\
\hline Hypertension & $18,721(88.1)$ & & & $678(83.3)^{* * *}$ & & \\
\hline Heart conditions & $13,266(62.4)$ & & & $466(57.3)^{*}$ & & \\
\hline High cholesterol levels & $11,653(54.8)$ & & & $368(45.2)^{* * *}$ & & \\
\hline Asthma & $6420(30.2)$ & & & $175(21.5)^{* * *}$ & & \\
\hline Chronic pain ${ }^{b}$ & $5639(26.5)$ & & & $215(26.4)$ & & \\
\hline Diabetes Type 2 & $5638(26.5)$ & & & $190(23.3)^{*}$ & & \\
\hline COPD/heavy asthma & $4846(22.8)$ & & & $124(15.2)^{* * *}$ & & \\
\hline Depression & $4206(19.8)$ & & & $178(21.9)$ & & \\
\hline Psychosis/alzheimers/addiction & $3396(16.0)$ & & & $185(22.7)^{* * *}$ & & \\
\hline Diabetes Type 1 & $3224(15.2)$ & & & $72(8.9)^{* * *}$ & & \\
\hline
\end{tabular}

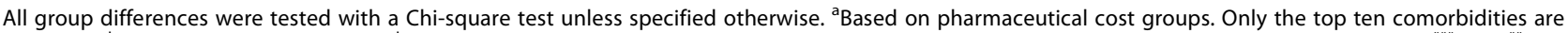
displayed, ${ }^{b}$ Excluding opiods, ${ }^{c}$ T-Test, ${ }^{d}$ Non-parametric T-test (Mann-Whitney U Test). Differences are significant at the significance levels $.001\left({ }^{* * *}\right)$, .01 $\left({ }^{* *}\right)$, and $.05\left({ }^{*}\right)$

chronically ill older adult patients and Table 4 shows the results for the subgroup with hip fracture. The results from both tables will be discussed below.

\section{Total group chronically ill older adult patients}

Age and sex rates differ between the groups; chronically ill older adult patients with LTC are older and more often female compared to the patients in the other groups; patients without aftercare are youngest (Table 3). The majority of the discharged patients received $\mathrm{CN}$ (39.1\%) and $14.3 \%$ received LTC in the first 90 days. Almost a third received no aftercare. Each of the other combinations was offered to less than $5 \%$ of the patients. Overall, more females received any of the six combinations of aftercare, whereas the distribution of male/female was more or less equal in the group without any of these combinations of care. People receiving GR or a combination of GR and CN were mostly admitted due to a hip fracture, cerebrovascular diseases or another injury or poisoning. Patients receiving LTC were mostly admitted due to injury/poisoning, clinical geriatrics (including dementia) or a hip fracture. Patients with none of the four types of aftercare were mostly admitted due to ischemia, CABG or PCI, cardiac arrhythmia, or disorders of the digestive system.

Mortality Within the first 90 days after discharge, the number of deaths is highest for patients who had a short stay in a LTC facility (38.2\%). In the $90-180$ day period, this dramatically drops to less than $8 \%$ and with $11 \%$, the number of deceased patients is the highest for the 'other' combination. The lowest mortality rates were seen in the $\mathrm{CN}$ and GR $+\mathrm{CN}$ groups. Patients with LTC have the highest age at death whereas patients without aftercare die youngest.

Readmissions We observe the lowest number of 90180 day readmissions for patients who had an ST or LTC. The highest clinical readmission rates are seen in the groups $\mathrm{GR}+\mathrm{CN}$ and GR. These rates exclude admissions to the rehabilitation ward. These patients are most often readmitted due to a hip fracture, cerebrovascular disease, or peripheral arterial occlusive disease (PAOD). 
Table 2 The 180 day post-discharge healthcare utilization

\begin{tabular}{|c|c|c|c|c|c|c|}
\hline \multirow[b]{2}{*}{ Measure } & \multicolumn{3}{|c|}{ Older adult with any admission in $2015(N=21,258)$} & \multicolumn{3}{|c|}{ Older adult admitted with hip fracture $(N=814)$} \\
\hline & N (\%) & Mean (SD) & Median [Range] & N (\%) & Mean (SD) & Median [Range] \\
\hline \multicolumn{7}{|l|}{ Hospital } \\
\hline Clinical admission & $10,955(51.5)$ & $24.4(29.2)$ & $12[1-179]$ & $608(74.7)^{* * *}$ & $44.9(35.1)$ & $38[1-179]$ \\
\hline ICU day & $1487(7.0)$ & $1.0(0.2)$ & $1[1-2]$ & $34(4.2)$ & $1.0(0)$ & $1[1-1]$ \\
\hline ER visit & $2612(12.3)$ & $1.3(0.7)$ & $1[1-9]$ & $60(7.4)$ & $1.2(0.4)$ & $1[1-2]$ \\
\hline Outpatient visit & $17,540(82.5)$ & $4.8(4.0)$ & $4[1-74]$ & $660(81.1)^{* * *}$ & $3.9(3.3)$ & $3[1-22]$ \\
\hline Day care treatment & $2647(12.5)$ & $1.7(2.4)$ & $1[1-77]$ & $49(6.0)$ & $1.4(0.7)$ & $1[1-4]$ \\
\hline Surgery & $4510(21.2)$ & $1.5(0.9)$ & $1[1-14]$ & $204(25.1)^{*}$ & $1.3(0.6)$ & $1[1-5]$ \\
\hline Laboratory tests & $13,697(64.4)$ & $10.1(7.4)$ & $9[1-48]$ & $487(59.8)$ & $10.6(7.7)$ & $10[1-38]$ \\
\hline Pathology tests & $167(0.8)$ & $1.0(0.2)$ & $1[1-2]$ & $<10$ & & \\
\hline CT-scan & $4577(21.5)$ & $1.4(0.9)$ & $1[1-14]$ & $103(12.7)^{* * *}$ & $1.2(0.5)$ & $1[1-4]$ \\
\hline MRI-scan & $1123(5.3)$ & $1.2(0.5)$ & $1[1-7]$ & $18(2.2)$ & $1.2(0.4)$ & $1[1-2]$ \\
\hline PET/CT-scan & $348(1.6)$ & $1.1(0.3)$ & $1[1-3]$ & $<10$ & & \\
\hline Other nuclear tests & $427(2.0)$ & $1.3(0.5)$ & $1[1-4]$ & $<10$ & & \\
\hline Other imaging & $12,668(59.6)$ & $2.8(2.7)$ & $2[1-39]$ & $621(76.3)$ & $2.8(2.3)$ & $2[1-21]$ \\
\hline Invasive diagnostics & $3057(14.4)$ & $1.4(1.0)$ & $1[1-18]$ & $58(7.1)$ & $1.3(0.7)$ & $1[1-4]$ \\
\hline Other non-invasive diagnostics & $11,961(56.3)$ & $2.7(2.6)$ & $2[1-42]$ & $322(39.6)^{* *}$ & $1.8(1.4)$ & $1[1-11]$ \\
\hline Rehabilitation days & $4224(19.9)$ & $29.2(23.4)$ & $25[1-161]$ & $499(61.3)^{* * *}$ & $34.6(21.9)$ & $29[1-155]$ \\
\hline \multicolumn{7}{|l|}{ Community home care } \\
\hline Nursing hours & $9675(45.5)$ & $26.8(55.5)$ & $0[0-8]$ & $367(45.1)$ & $18.8(34.2)$ & $5.9[0.2-351.9]$ \\
\hline Care giving hours & $10,216(48.1)$ & $94.3(128.7)$ & 0 [0-59] & $377(46.3)$ & $81.8(110.9)$ & $56.5[0.1-1431.5]$ \\
\hline \multicolumn{7}{|l|}{ LTC at home or facility } \\
\hline Nursing hours & $439(2.1)$ & $1551.5(2531.0)$ & $665[5-21,329]$ & $14(1.7)$ & $392.9(466.3)$ & $203[45-1528]$ \\
\hline Care giving hours & $676(3.2)$ & $6510.0(6710.7)$ & $4230[15-43,063]$ & $16(2.0)$ & $3458.1(3802.1)$ & $2261.5[105-13,890]$ \\
\hline $\mathrm{HCl}$ package 3 , hours & $388(1.8)$ & $108.7(70.5)$ & $122[1-185]$ & $31(3.8)$ & $114.8(66.5)$ & 119 [17-184] \\
\hline $\mathrm{HCl}$ package 4 , hours & $1152(5.4)$ & $115.0(62.1)$ & $124[1-285]$ & $93(11.4)^{*}$ & $102.5(60.8)$ & $110[1-195]$ \\
\hline $\mathrm{HCl}$ package 5 , hours & $832(3.9)$ & $110.9(60.6)$ & 117 [1-223] & $90(11.1)$ & $111.0(60.5)$ & $107.5[1-195]$ \\
\hline $\mathrm{HCl}$ package 6 , hours & $1227(5.8)$ & $101.9(62.2)$ & $102[1-208]$ & $93(11.4)$ & $103.6(59.9)$ & $103[2-208]$ \\
\hline $\mathrm{HCl}$ package 7 , hours & $50(0.2)$ & $96.6(63.5)$ & 93 [1-184] & $<10$ & & \\
\hline $\mathrm{HCl}$ package 8 , hours & $24(0.1)$ & $105.9(69.3)$ & 132 [1-199] & $<10$ & & \\
\hline $\mathrm{HCl}$ package 9 , hours & $90(0.4)$ & $65.4(52.4)$ & $48[1-181]$ & $26(3.2)$ & $66.7(51.6)$ & $63.5[6-173]$ \\
\hline $\mathrm{HCl}$ package 10 , hours & $60(0.3)$ & $25.3(32.7)$ & $12[1-166]$ & $<10$ & & \\
\hline Short stay nursing home & $1037(4.9)$ & 43.4 (33.3) & 38 [1-184] & $44(5.4)$ & 45.3 (31.9) & 45 [1-156] \\
\hline \multicolumn{7}{|l|}{ GP care } \\
\hline Consultations & $19,276(90.7)$ & $8.1(6.4)$ & $7[1-71]$ & $707(86.9)^{* *}$ & $7.5(6.1)$ & $6[1-40]$ \\
\hline Home visits & $13,851(65.2)$ & $4.1(3.8)$ & 3 [1-53] & $543(66.7)$ & $3.9(3.3)$ & 3 [1-19] \\
\hline
\end{tabular}

All group differences were tested with a Chi-square test. Differences are significant at the significance levels $.001\left({ }^{* * *}\right), .01\left({ }^{* *}\right)$, and $.05\left({ }^{*}\right)$. The health care intensity packages are a predefined package of healthcare. The higher the package number, the more intense healthcare a person receives. It ranges from living with daily assistance and nursing care to intensive palliative care in a home

$C T$-scan computerized tomography scan, ER emergency room, GP general practitioner, $H C l$ health care intensity, ICU intensive care unit, $L T C$ long-term care, $M R I-$ scan magnetic resonance imaging scan

\section{Chronically ill older adult patients with hip fracture}

The majority of the discharged patients who were admitted due to a hip fracture, received community nursing care (30.7\%), 29\% received LTC and $11.4 \%$ received no aftercare in the form of GR, CN, LTC or ST (Table 4).
Again, the age and sex rates differ over the multiple categories.

Mortality The highest $90-180$ day mortality rates are seen in the 'ST' and 'other' groups. These patients are 


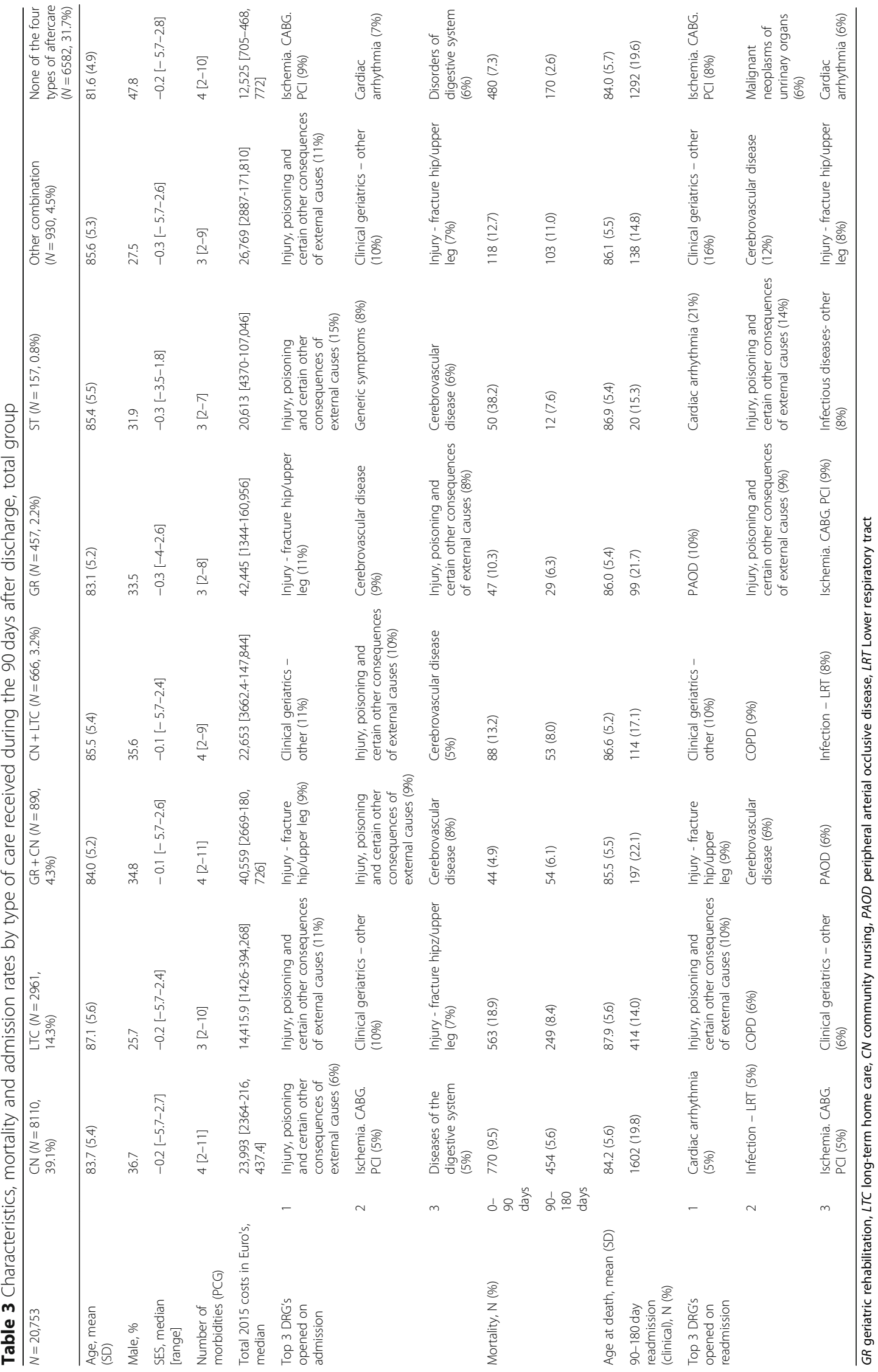




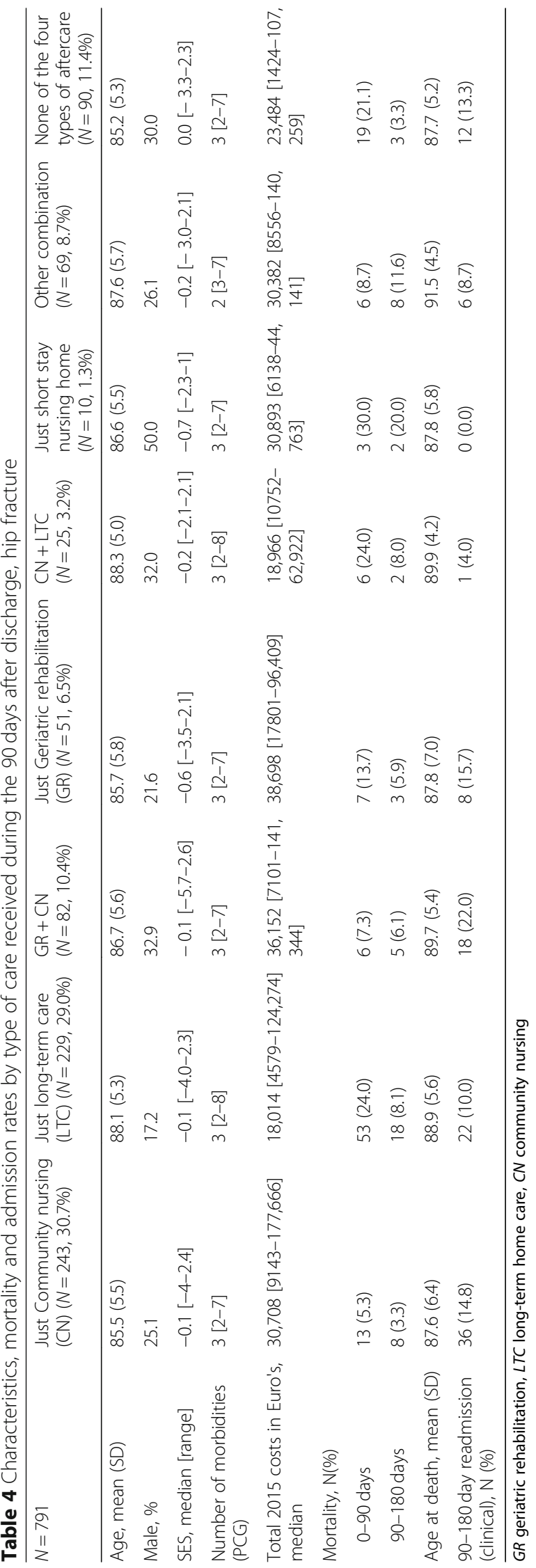


younger and have less morbidities compared to the other groups. The lowest mortality was seen in patients with $\mathrm{CN}$ or none of the four types of aftercare (both 3.3\%).

Readmissions The highest readmission rates are seen in the GR + CN group (22\%). Patients with an ST or CN + LTC are less often readmitted compared to the other groups.

\section{Discussion}

This paper aimed to describe the post-discharge healthcare trajectories of chronically ill older adult patients and describe the mortality and readmission rates for the most common 90 day-post-discharge care arrangements. Our results seem to indicate that chronically ill older adult patients with any admission or an admission due to hip fracture, who receive $\mathrm{CN}$ in the first 90 days, less often die compared to patients receiving other types or no type of aftercare. However, chronically ill older adult patients receiving these types of aftercare also have one of the highest readmission rates.

Our hypothesis, that older adults with any type of predefined aftercare would have less readmissions and lower mortality rates than older adults receiving no aftercare, is not confirmed. On the contrary, older adults without aftercare less often die within 180 days.

An explanation for this could be that this group is in lesser need of care compared to the other groups. They are on average younger, a higher proportion is male, and the reasons for admission differ from the other groups. Another explanation could be that these older adults rely on informal care from for instance their spouse. However, they die at a younger age compared to older adults that did receive any of these types of intense care. Also, a large proportion is readmitted which suggests that they are not better off per se.

Describing care trajectories is especially important when we want to find flaws in the continuity of care and ultimately reduce fragmentation and optimize care. Older adult patients often suffer from multiple conditions and therefore receive care from multiple providers. This means that there is potential danger of fragmentation of care. A seamless continuity of care is most at risk during the patients' transition from an institutional care setting to the home [19]. Although causality cannot be established from these data, our results coincide with previous research, that shows that a good transfer to home care and the use of a community nurse could reduce deaths and improve functional outcomes in older adults [6].

Research also shows that especially older adult patients admitted due to heart failure or with functional disability, which can be expected after hip fracture, deserve extra attention when transferring from the hospital to the home setting, especially with regards to avoidable readmissions [20]. Unfortunately, we know that transfer of care after discharge to the primary or long-term care setting is not always regulated sufficiently to guarantee continuity of care [21] and that in order for care transition programs to be effective, they require a more tailor-made approach [22].

Our inclusion criteria led to the inclusion of a heterogeneous group, as we could, for instance, see from the different diagnoses at admission. Differences in morbidity make it difficult to interpret the results. With our subgroup analyses we shed more light onthis issue. Postdischarge healthcare utilization for chronically ill older adult patients with a hip fracture differs from the total group on several expected differences, such as healthcare utilization that seems to be more specific for a hip fracture patient and the higher costs that accompany them.. However, even though the two subsamples might not be one-on-one comparable, the issue raised for the total group of chronically ill older adult patients still applies to the group admitted due to a hip fracture, where still a proportion of patients does not receive aftercare in the form of GR, CN, ST or LTC, although to a lesser extent.

\section{Strengths and limitations}

Because we used data from one of the largest Insurance companies in the Netherlands with a $30 \%$ market share, we were able to analyze a large and representative group of the older adults in the Netherlands. Also, the fact that the company not only collected claims data on a DRG level but on healthcare activity level means that we can actually analyze the chain of healthcare in much greater detail. We were unable to include claims made under the social support act. This is healthcare reimbursed by municipalities which focuses on providing assistance in daily living (for instance grocery or meal services or cleaning support) in order to let the older adult live independently for as long as possible.

In 2015, an average of 22\% of all persons aged 75 and over resided in a long-term care facility which is similar to but slightly higher than the $18 \%$ of the older adults we identified residing in nursing homes. Our inclusion criterion 'using medications from at least two different pharmacybased cost groups' most likely lead to an under-sampling of older adults residing in long-term care facilities. This is because in those facilities, the medication costs are directly claimed with the facility and not with the insurance company. Also, by using pharmacy-based cost groups, not all drugs administered in the inpatient setting could be used to identify morbidities of the FE. These two reasons lead to a lower morbidity rate for cancer and dementia. This does not mean that a large part of our subjects does not suffer from these diseases; it means that we were unable to identify them. 


\section{Conclusions}

The organization of post-discharge healthcare for chronically ill older adult patients may not be organized sufficiently to guarantee appropriate care to restore functional activity. Although receiving aftercare is not a clear predictor of readmissions in our study, the results do seem to indicate that older adults receiving community nursing in the first 90 days less often die compared to chronically ill older adult patients with other types of aftercare or no aftercare. Therefore, an area for improvement could be the deployment of a home nurse after hospital admission for these patients in order to bridge the transfer from hospital to the primary care setting. More research is however necessary to examine predictors of readmissions and mortality in both older adult patients discharged from hospital.

\section{Abbreviations}

CN: Community nursing; ER: Emergency room; GP: General practitioner; GR: Geriatric rehabilitation; HCl: Healthcare intensity; ICU: Intensive care unit; LRT: Lower respiratory tract; LTC: Long-term care; PAOD: Peripheral arterial occlusive disease; SCP: Social and Cultural Planning Office;

SES: Socioeconomic status; ST: Short stay

\section{Acknowledgements}

We thank Zilveren Kruis Achmea for making it possible to access and analyze their data and for their support. The lead author affirms that the manuscript is an honest, accurate, and transparent account of the study being reported; that no important aspects of the study have been omitted; and that any discrepancies from the study as planned (and, if relevant, registered) have been explained.

\section{Authors' contributions \\ YdM, ASG, FA and WJ were involved in the initial design of the study. YdM analyzed the data. WJ provided guidance on-site, checked syntaxes and managed the data. YdM, ASG, FA and WJ were continuously involved during the conduct of the study. SEJAdR was involved as an external expert to interpret the results and provide input for the discussion. SEJAdR, GPW and PPTJ contributed greatly to defining the frail older adult patient and played a leading role in the decision to add additional hip fracture analyses. YdM prepared the manuscript. All co-authors reviewed this multiple times. All authors read and approved the final manuscript.}

\section{Funding}

This study was supported by Ministry of Health, Welfare and Sport, the Netherlands. The organization did not participate in the design and conduct of the study; collection, management, analysis, and interpretation of the data; preparation, review, or approval of the manuscript; and decision to submit the manuscript for publication.

\section{Availability of data and materials}

The data that support the findings of this study are available from insurance company Zilveren Kruis Achmea, but restrictions apply to the availability of these data, which were used under license for the current study, and so are not publicly available. Data are however available from the authors upon reasonable request and with permission of Zilveren Kruis Achmea.

\section{Ethics approval and consent to participate}

Under Dutch national law (Medical Research Involving Human Subjects Act (WMO)), approval of an institutional review board for this study was not required. This study is not subject to theMedical Research in Human Subjects as subjects were not subjected to actions or interventions. Also, no rules of conduct were imposed on them. Consent to participate is deemed unnecessary according to national regulations. To ensure the privacy of patient, researchers received non-identifiable patient data. According to
Dutch law no (written) informed consent to publish the material is needed in case anonymized data are used. Also, the insurance company has provided consent for publication under the condition that the extracted data will not be published with recognizable hospitals or patients.

\section{Consent for publication}

Not applicable.

\section{Competing interests}

The authors declare that they have no competing interests.

\section{Author details}

${ }^{1}$ Radboud university medical center, Radboud Institute for Health Sciences, IQ healthcare, P.O. Box 9101, 114, 6500, HB, Nijmegen, the Netherlands. ${ }^{2}$ Division of Health Care, Achmea Insurances, Zwolle, The Netherlands. ${ }^{3}$ University of Groningen, University Medical Center Groningen, University Center for Geriatric Medicine, Groningen, The Netherlands. ${ }^{4} \mathrm{AMC}$ Department of Internal Medicine, Geriatrics, Amsterdam, NL, The Netherlands.

Received: 7 March 2019 Accepted: 30 September 2019

Published online: 15 October 2019

References

1. DeFrances CJ, Lucas CA, Buie VC, Golosinskiy A. 2006 national hospital discharge survey. Natl Health Stat Report. 2008;5(July):1-20.

2. Sager MA, Franke T, Inouye SK, Landefeld CS, Morgan TM, Rudberg MA, Siebens $\mathrm{H}$, Winograd $\mathrm{CH}$. Functional outcomes of acute medical illness and hospitalization in older persons. Arch Intern Med. 1996;156(6):645-52.

3. McCusker J, Kakuma R, Abrahamowicz M. Predictors of functional decline in hospitalized elderly patients: a systematic review. J Gerontol Ser A Biol Med Sci. 2002;57(9):M569-77.

4. Dale C, Prieto-Merino D, Kuper H, Adamson J, Bowling A, Ebrahim S, Casas JP. Modelling the association of disability according to the WHO International Classification of Functioning, Disability and Health (ICF) with mortality in the British Women's Heart and Health Study. J Epidemiol Community Health. 2012:66(2):170-5.

5. Ilinca S, Calciolari S. The patterns of health care utilization by elderly Europeans: frailty and its implications for health systems. Health Serv Res. 2015;50(1):305-20.

6. Buurman BM, Hoogerduijn JG, de Haan RJ, Abu-Hanna A, Lagaay AM, Verhaar HJ, Schuurmans MJ, Levi M, de Rooij SE. Geriatric conditions in acutely hospitalized older patients: prevalence and one-year survival and functional decline. PLoS One. 2011;6(11):e26951.

7. Coleman EA, Parry C, Chalmers S, Min S-J. The care transitions intervention: results of a randomized controlled trial. Arch Intern Med. 2006;166(17):1822-8.

8. Makai P, Melis RJ, O-RM GM. Developing a frailty index for healthcare claims data. Nijmegen: Radboudumc; 2014.

9. Lamers LM, van Vliet RC. The pharmacy-based cost group model: validating and adjusting the classification of medications for chronic conditions to the Dutch situation. Health policy. 2004;68(1):113-21.

10. [ATC-reference file FCGs equalization model 2016] [https://www. zorginstituutnederland.nl/publicaties/publicatie/2017/09/01/fkg-atcreferentiebestand-somatische-zorg-2016\%2D\%2D-aangepast]. Accessed March 2017

11. Van Campen C. Frail Elderly; 2011

12. Stuck $A E$, lliffe $S$. Comprehensive geriatric assessment for older adults. BMJ. 2011;343.d6799.

13. Ellis G, Whitehead MA, Robinson D, O'Neill D, Langhorne P. Comprehensive geriatric assessment for older adults admitted to hospital: meta-analysis of randomised controlled trials. Bmj. 2011;343:d6553.

14. Social and Cultural Planning Office of the Netherlands: Statusscores. 2009. https://www.scp.nl/Onderzoek/Statusscores. Accessed Mar 2016.

15. de Man Y, Atsma F, Oosterveld-Vlug MG, Brom L, Onwuteaka-Philipsen BD, Westert GP, Groenewoud AS. The Intensity of Hospital Care Utilization by Dutch Patients With Lung or Colorectal Cancer in their Final Months of Life. Cancer Control. 2019;26(1):1073274819846574.

16. [Geriatric rehabilitation] [https://www.zorginstituutnederland.nl/Nerzekerde+ zorg/g/geriatrische-revalidatiezorg-zvw]. Accessed Oct 2018.

17. [Short stay] [https://www.zorginstituutnederland.nI/Nerzekerde+zorg/v/ verblijf-zvw]. Accessed Oct 2018. 
18. [Long-term nursing care and assitance in daily living for adults] [https://www.informatielangdurigezorg.nl/volwassenen/verplegingverzorging]. Accessed Oct 2018.

19. Forster AJ, Murff HJ, Peterson JF, Gandhi TK, Bates DW. The incidence and severity of adverse events affecting patients after discharge from the hospital. Ann Intern Med. 2003;138(3):161-7.

20. van der Ven M, Schoon Y, Olde Rikkert M. Unplanned readmissions in frail elderly: retrospective analysis of admissions in a teaching hospital. Ned Tijdschr Geneeskd. 2015;159:A9211.

21. Health and Youth Care Inspectorate. Continuity of care for frail elderly from the hospital to nursing and care homes, home care and GPs are not guaranteed. Utrecht: Inspectie voor de Gezondheidszorg; 2015.

22. Borkenhagen LS, McCoy RG, Havyer RD, Peterson SM, Naessens JM, Takahashi PY. Symptoms reported by frail elderly adults independently predict 30-day hospital readmission or emergency department care. J Am Geriatr Soc. 2018;66(2):321-6.

\section{Publisher's Note}

Springer Nature remains neutral with regard to jurisdictional claims in published maps and institutional affiliations.

Ready to submit your research? Choose BMC and benefit from:

- fast, convenient online submission

- thorough peer review by experienced researchers in your field

- rapid publication on acceptance

- support for research data, including large and complex data types

- gold Open Access which fosters wider collaboration and increased citations

- maximum visibility for your research: over $100 \mathrm{M}$ website views per year

At BMC, research is always in progress.

Learn more biomedcentral.com/submissions 